\title{
The "dual-spot" Aethalometer: an improved measurement of aerosol black carbon with real-time loading compensation
}

L. Drinovec et al.

Correspondence to: L. Drinovec (luka.drinovec@aerosol.si) and G. Močnik (grisa.mocnik@aerosol.si) 
25 The filter loading effect is determined by the $B C(A T N)$ method for measurement campaigns 26 conducted at different types of the measurement site (roadside, urban background, rural 27 background, regional background) in Klagenfurt (Austria), Anaheim (USA), Payerne (Switzerland), 28 Sonnblick (Austria), Kathmandu (Nepal). Uncompensated BC data as measured by the AE33 with the 29 detector under spot S1 was fitted using a linear function in the ATN range from 4.4 to 45 . The filter 30 loading effect is determined as the relative slope $R S$ (Eq. 3). 


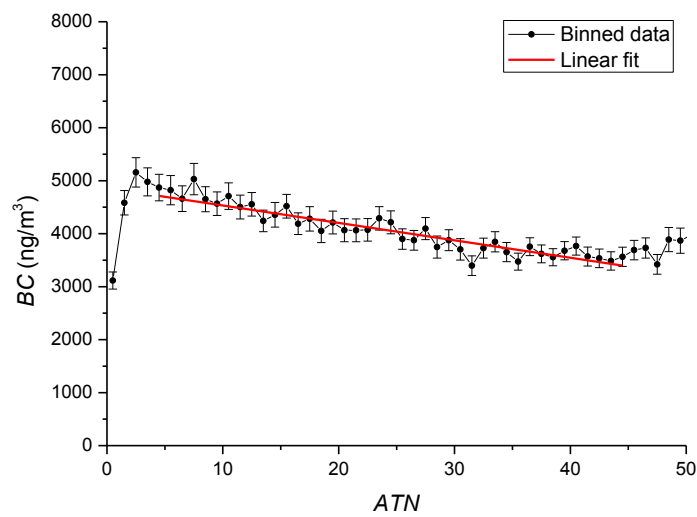

Figure S1. $B C(A T N)$ analysis of the filter loading effect for the campaign in Klagenfurt (Austria) from $\left.14^{\circ} 19^{\prime} 05.7^{\prime \prime E}, 446 \mathrm{~m} \mathrm{ASL}\right)$. The station is located in the middle of a crossroad and is strongly

37 influenced by local traffic. During winter the site is strongly influenced by biomass burning from residential heating. Average BC data for each ATN bin (1 ATN unit wide) and the linear fit of the raw data are presented. 


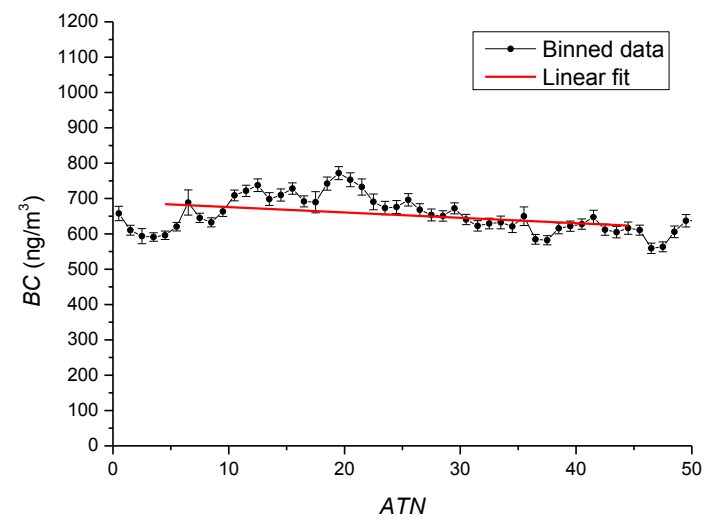

Figure S2. $B C(A T N)$ analysis of the filter loading effect for the campaign in Anaheim (California, USA) from 1-9 July 2012. The Anaheim station is located in an urban environment ( $33^{\circ} 49^{\prime} 50^{\prime \prime} \mathrm{N}$, $117^{\circ} 56^{\prime} 18^{\prime \prime W}, 39 \mathrm{~m} \mathrm{ASL}$ ). Average BC data for each ATN bin (1 ATN unit wide) and the linear fit of the raw data are presented.

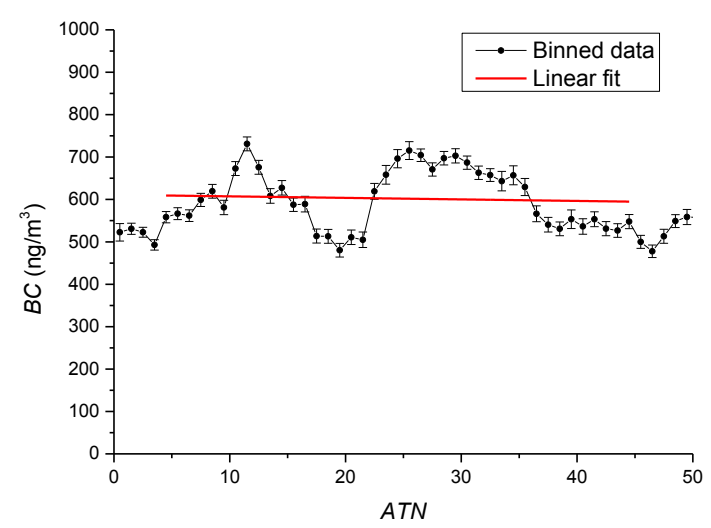

Figure S3. $B C(A T N)$ analysis of the filter loading effect for the campaign in Payerne (Switzerland) from 15 June -5 July 2012 . The Payerne aerological station $\left(46.82^{\circ} \mathrm{N}, 6.95^{\circ} \mathrm{E}, 491 \mathrm{~m} \mathrm{ASL}\right)$ is a rural background air quality monitoring station located in Southwestern Switzerland, on the Swiss plateau between the Jura and the Alps. It lies about $1 \mathrm{~km}$ south-east of the small rural town of Payerne. The site is surrounded by agricultural fields (grassland and crops), forests and small villages. Average BC data for each ATN bin (1 ATN unit wide) and the linear fit of the raw data are presented. 


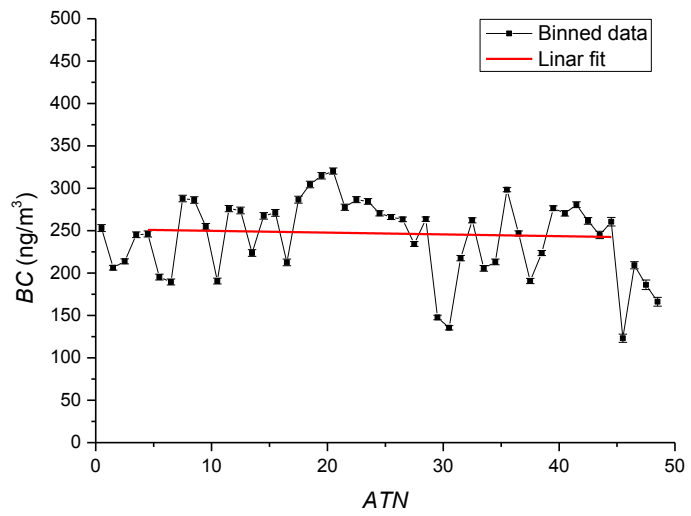

54

55 Figure S4. BC(ATN) analysis of the filter loading effect for the campaign in Sonnblick (Austria) from

1 July to 31 August 2013. The Sonnblick observatory is a background station located in the high alpine environment $\left(47^{\circ} 03^{\prime} 15^{\prime \prime} \mathrm{N}, 12^{\circ} 57^{\prime} 27^{\prime \prime} \mathrm{E}, 3106 \mathrm{~m} \mathrm{ASL}\right)$. Measurements at this location allow the determination of the composition of the mid-troposphere, frequently reaching into the free troposphere. Average BC data for each ATN bin (1 ATN unit wide) and the linear fit of the raw data

60 are presented. 


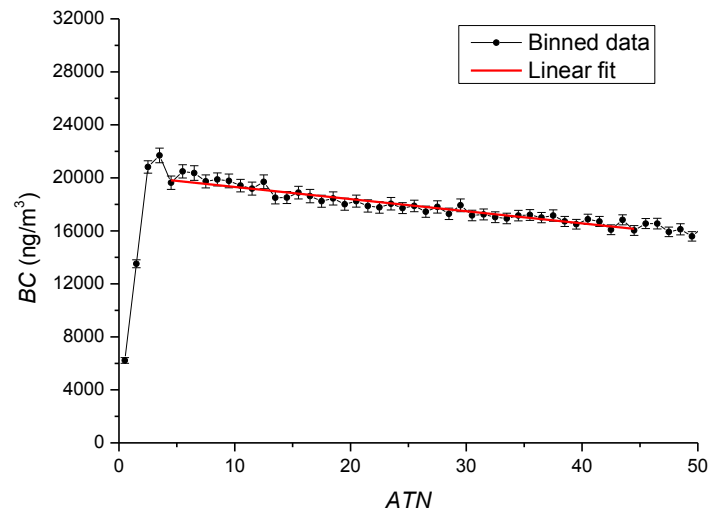

63 Figure S5. $B C(A T N)$ analysis of the filter loading effect for the campaign in Kathmandu (Nepal) from setting ), this site often receives the outflows of three major cities in the valley (Kathmandu, Lalitpur and Bhaktapur) and occasionally receives regional air masses. BC emissions originate from a combination of residential cooking, heating, brick factories, small diesel-powered generator sets, open burning of solid waste and traffic. Average BC data for each ATN bin (1 ATN unit wide) and the linear fit of the raw data are presented. 
73 Table S1. Average filter loading effect as determined with the $B C(A T N)$ analysis for different

74 measurement sites and seasons.

\begin{tabular}{|l|l|l|l|}
\hline Location & $B C(A T N)$ relative slope $R S$ & Site description & Season \\
\hline Klagenfurt (Austria) & $-0.0069+/-0.0007$ & Roadside & Winter \\
\hline Anaheim (USA) & $-0.0033+/-0.0003$ & Urban & Summer \\
\hline Payerne (Switzerland) & $-0.0013+/-0.0004$ & Rural background & Summer \\
\hline Sonnblick (Austria) & $-0.0017+/-0.0002$ & Regional background & Summer \\
\hline Kathmandu (Nepal) & $-0.0047+/-0.0003$ & Urban & Winter \\
\hline
\end{tabular}

75 
Table S2. Mass absorption cross-section values used in the AE33.

\begin{tabular}{|l|l|l|}
\hline Channel & Wavelength $(\mathrm{nm})$ & $\sigma_{\text {air }}\left(\mathrm{m}^{2} \mathrm{~g}^{-1}\right)$ \\
\hline 1 & 370 & 18.47 \\
\hline 2 & 470 & 14.54 \\
\hline 3 & 520 & 13.14 \\
\hline 4 & 590 & 11.58 \\
\hline 5 & 660 & 10.35 \\
\hline 6 & 880 & 7.77 \\
\hline 7 & 950 & 7.19 \\
\hline
\end{tabular}

81

The mass absorption cross-section values $\sigma_{\text {air }}$ denote the mass absorption cross-section of aerosols freely suspended in the atmosphere. The values used in the Aethalometer assume an inverse dependence on the wavelength - that is, a "black" sample with an Ångström exponent equal to unity (Moosmüller et al., 2011). The relationship between the absorption and mass was determined by optical measurements of transmission and thermal measurements of samples, where the non-refractory constituents of the carbonaceous sample were removed (Gundel et al., 1981; Gundel et al., 1984). The pollutants in ambient air and combustion source exhausts were sampled on quartz fiber filters and analyzed. The non-destructive optical measurement was the laser transmission method carried out at room temperature. The thermal method employed was the evolved gas analysis (EGA) in oxygen (Malissa et al., 1976). EGA was performed on the non-treated filters and on the filters sequentially extracted 
by benzene and a mixture of methanol-chloroform. The most refractory peak in the extracted filter thermograms was used to quantify black carbon. The mass attenuation cross section for the laser was thus obtained: $\sigma=(23.9 \pm 2.0) \mathrm{m}^{2} \mathrm{~g}^{-1}$. The high value is typical for the attenuation measurement setups using collimated laser beams (Gundel et al., 1984). In the first Aethalometer, using an incandescent lamp and a green band-pass filter (Hansen et al., 1984), the mass attenuation cross section was determined to be $10 \mathrm{~m}^{2} \mathrm{~g}^{-1}$ at $530 \mathrm{~nm}$. In the ensuing commercial embodiment of the Aethalometer, again using an incandescent lamp without any filters, the mass attenuation cross section was determined to be $19 \mathrm{~m}^{2} \mathrm{~g}^{-1}$ (Babich et al., 2000). When the $880 \mathrm{~nm}$ LED source was introduced in the Aethalometers AE16, AE21, AE22, AE31 and AE42, the mass attenuation cross section at this wavelength was determined by comparison with older-type Aethalometers to be 16.6 $\mathrm{m}^{2} \mathrm{~g}^{-1}$ (Hansen, 2005).

The path length of a photon and hence the probability for the photon to be absorbed by a particle increases in the filter matrix due to the scattering of light by the filter fibers. This can be empirically taken into account using a single parameter, describing the enhancement of absorption as a multiplication factor $C$ (Weingartner et al., 2003): $\sigma=C \sigma_{\text {air. }}$ The same mass of the sample absorbs $C$ times more when the particles are embedded in the filter matrix than when they are freely suspended in the air. The separation of the $C$ and $\sigma_{\text {air }}$ parameters, using the value of $C=2.14$ (determined in Weingartner et al., 2003) for legacy type Aethalometers, such as AE31, determines the mass absorption cross-section of freshly emitted $\mathrm{BC} \sigma_{\text {air }}=7.77 \mathrm{~m}^{2} / \mathrm{g}$. We use this parameter in the AE33 in addition to the parameter $C$, determined for the new TFE-coated glass fiber filter tape (see section "3.3 Influence of the filter material"). We measured ambient BC concentrations using collocated Aethalometers AE31 and AE33, then determined the parameter $C$ for the AE33 from these ambient data. 
Optical measurements in the infra-red part of the spectrum should be used to convert the optical measurement into the mass concentration, as the contribution of sample components other than black carbon is negligible at these wavelengths (Sandradewi et al., 2008a; Sandradewi et al., 2008b; Fialho et al., 2005; Yang et al., 2009; and references therein). The relationship between the mass concentration of $\mathrm{BC}$ and the optical absorption can be determined by comparing the filter photometer measurements with those obtained by thermal-optical analysis (Sciare et al., 2011). However, as the determination of elemental carbon (EC) depends on the thermal-optical analysis method, sometimes with large differences (Bae et al., 2009), the determination of the mass absorption cross-section also depends on the thermal-optical method employed. Additionally, the season and the sample composition (Bae et al., 2009; Chiappini et al., 2014) may influence the determination of EC; and the mass absorption cross-section may depend on the aerosol mixing state and size (Bond and Bergstrom, 2006). Concurrent determination of EC in filter samples with an thermal-optical method, and the Aethalometer measurement of optical absorption allow the sitespecific determination of the mass absorption cross-section, which is specific to the thermal-optical method employed - this procedure is often employed in source apportionment campaigns, where mass closure is attempted (Sciare et al., 2011).

\section{Determination of the face velocity ratio factor (FVRF)}

The loading effect compensation algorithm is sensitive to correct measurement of the sample flow through the spots. The flow through the spot 2 is especially susceptible to errors since it is calculated as a difference between total flow and flow through the spot1. FVRF is used to compensate for flow measurement uncertainty (Article, Equation 11):

$$
F V R F=\left(\frac{A T N_{\text {spot } 2}}{A T N_{\text {spot } 1}}\right)_{A T N=0} \frac{F_{1}}{F_{2}}
$$


143 The calculation of FVRF is based on the fact that at small filter loadings the attenuation is 144 proportional to the flow through the spot. Because of the transients on the fresh spot, the first ATN measurements (where $A T N_{1}<A T N_{\mathrm{f} 1}$ ) are omitted from the analysis. Data with $A T N_{1}$ (attenuation for channel1, spot1) between the lower limit $A T N_{\mathrm{f} 1}$ and upper limit $A T N_{\mathrm{f} 2}$ are used for determination of FVRF (Figure S6). The actual parameter which tells us the correct flow ratio is the intercept of the linear fit of $A T N_{\text {spotz }} / A T N_{\text {spot1 }}$ versus $A T N_{\text {spot1 }}$ (Figure S6). The average $F V R F$ for channels 2 to 6 is used for further calculations.

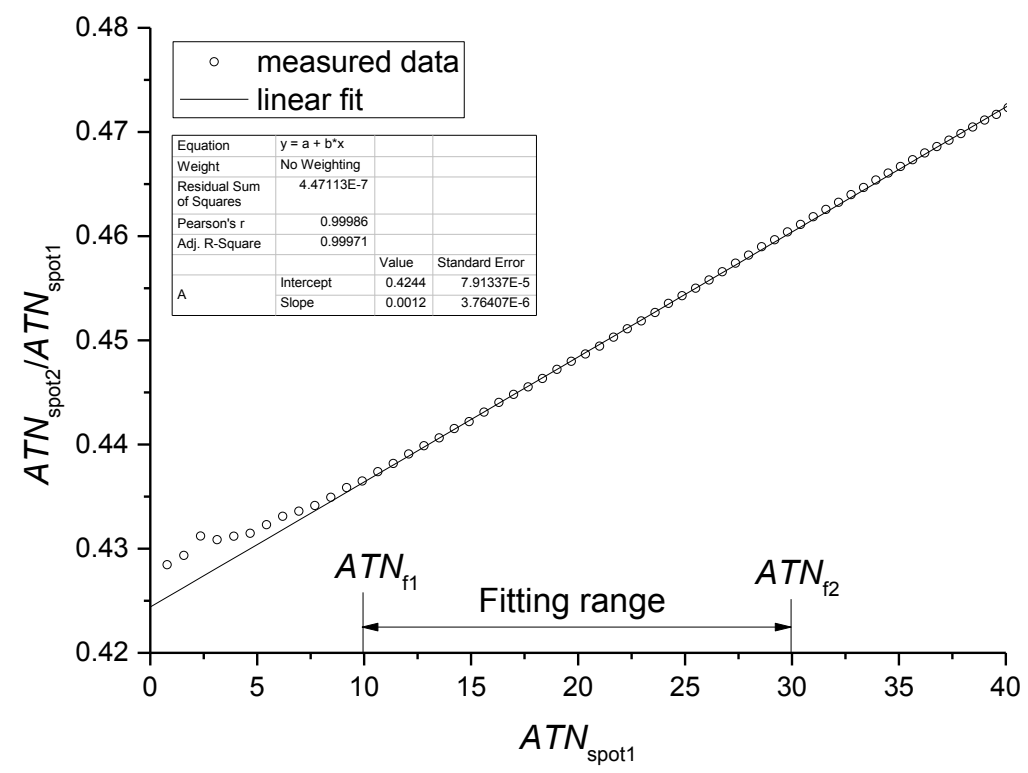

Figure S6. An example of fitting $A T N_{\text {spot2 }} / A T N_{\text {spot1 }}$ versus $A T N_{\text {spot1 }}$ data to obtain the intercept value. The intercept $\left(A T N_{\text {spot2 }} / A T N_{\text {spot1 }}\right)_{\text {ATN=0 }}$ represents a real flow ratio $F_{\text {spot } 2} / F_{\text {spot1 }}$.

FVRF values differ slightly between the instruments and spots. Here is an example of mean values and standard deviation of FVRF for 5 different instruments: $1.001 \pm 0.025,1.059 \pm 0.011,1.063 \pm$ $0.001,1.017 \pm 0.006$ and $0.979 \pm 0.02$. If the flow ratio is not compensated, a wrong value of parameter $k$ is obtained. The influence of $2 \%$ change of flow ratio on the parameter $k$ is presented in Figure S7. 


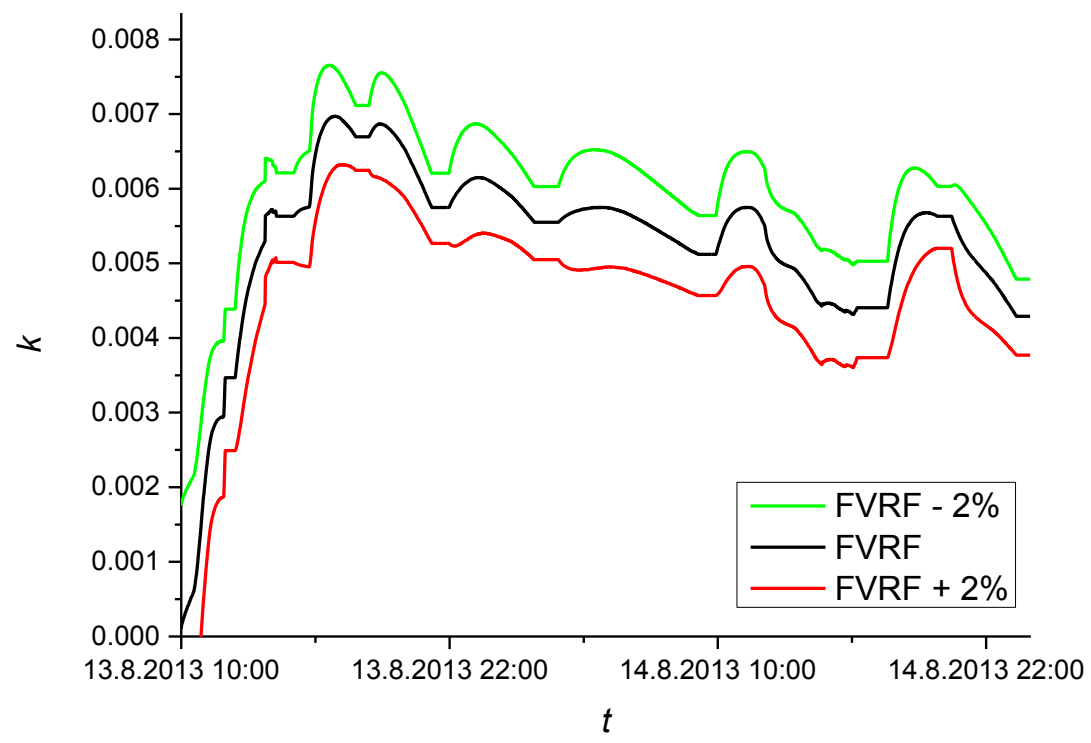

159

160 Figure S7. Illustration of the sensitivity of a dual spot loading effect compensation algorithm to

a $2 \%$ change in the face velocity ratio factor (FVRF).

\section{Weighing method for loading effect compensation parameter $k$}

Determination of the parameter $k$ at low filter loadings is very susceptible to small measurement errors. When more and more material is collected on the spot, the filter loading effect is easier to measure using the dual spot approach. To reduce the uncertainty of the parameter $k$ at low

167 attenuations, a weighting method is applied (main body of the article, Equation 12). Both weighted 168 and un-weighted values of parameter $k$ are presented on Figure $S 8$.

For $A T N_{1}<A T N_{\mathrm{f} 2}$ a value of $k_{\text {old }}$, which is obtained from the previous filter spot, is reported: 
171 For $A T N_{1}>A T N_{\mathrm{f} 2}$ a weighted value of the parameter $k$ is used, which takes into account the $k_{\text {old }}$ and

172 the un-weighted value of parameter $k$. The default value is $A T N_{\mathrm{f} 2}=30$. Progressively, as the

173 attenuation increases, less and less of $k_{\text {old }}$ is incorporated into $k_{\text {weighted: }}$

174

$k_{\text {weighted }}=\frac{\left(A T N_{T A}-A T N_{1}\right) k_{o l d}+\left(A T N_{1}-A T N_{\mathrm{f} 2}\right) k}{\left(A T N_{T A}-\mathrm{ATN}_{\mathrm{f} 2}\right)}$.

175 At the time of full spot loading, the weighted value of $k$ becomes equal to the instantaneous (un-

176 weighted) value:

177

$k_{\text {weighted }}\left(A T N_{1}=A T N_{T A}\right)=k$.

178

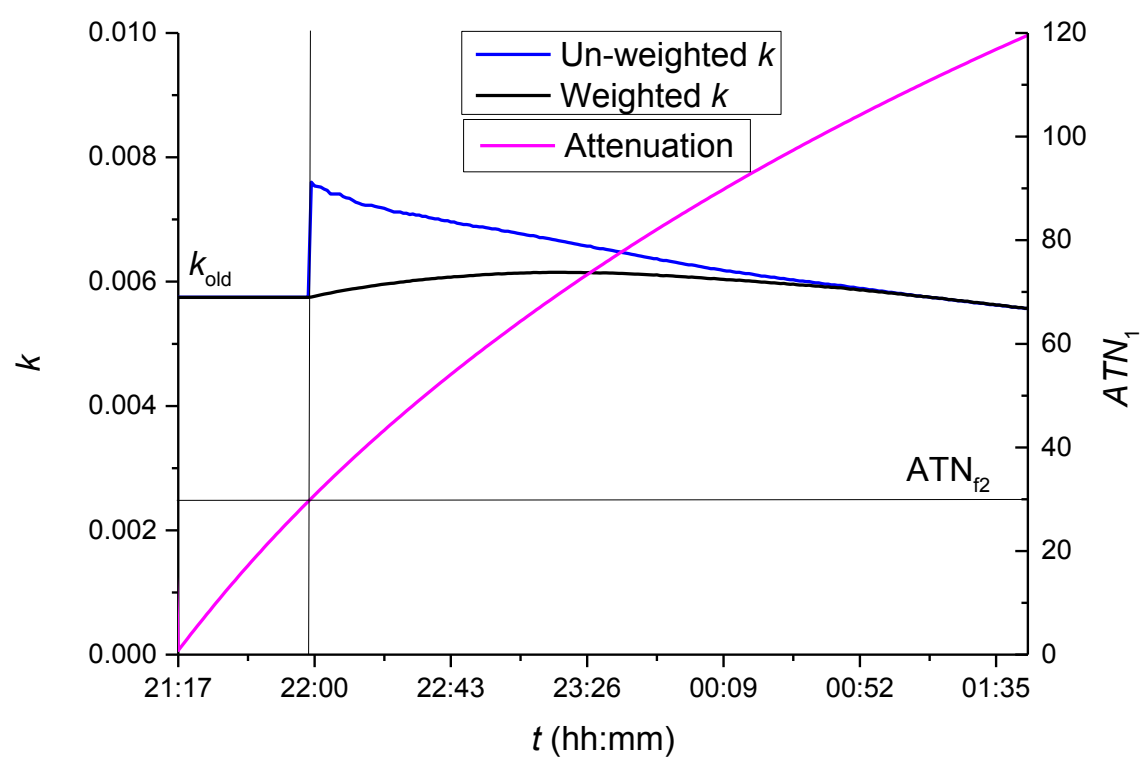

179

Figure S8. Example of the instantaneous and the weighted value of the parameter $k$ during spot

loading. For $A T N_{1}<A T N_{\mathrm{f} 2}$ the $\mathrm{k}$ value from the previous spot is used. For attenuations between 


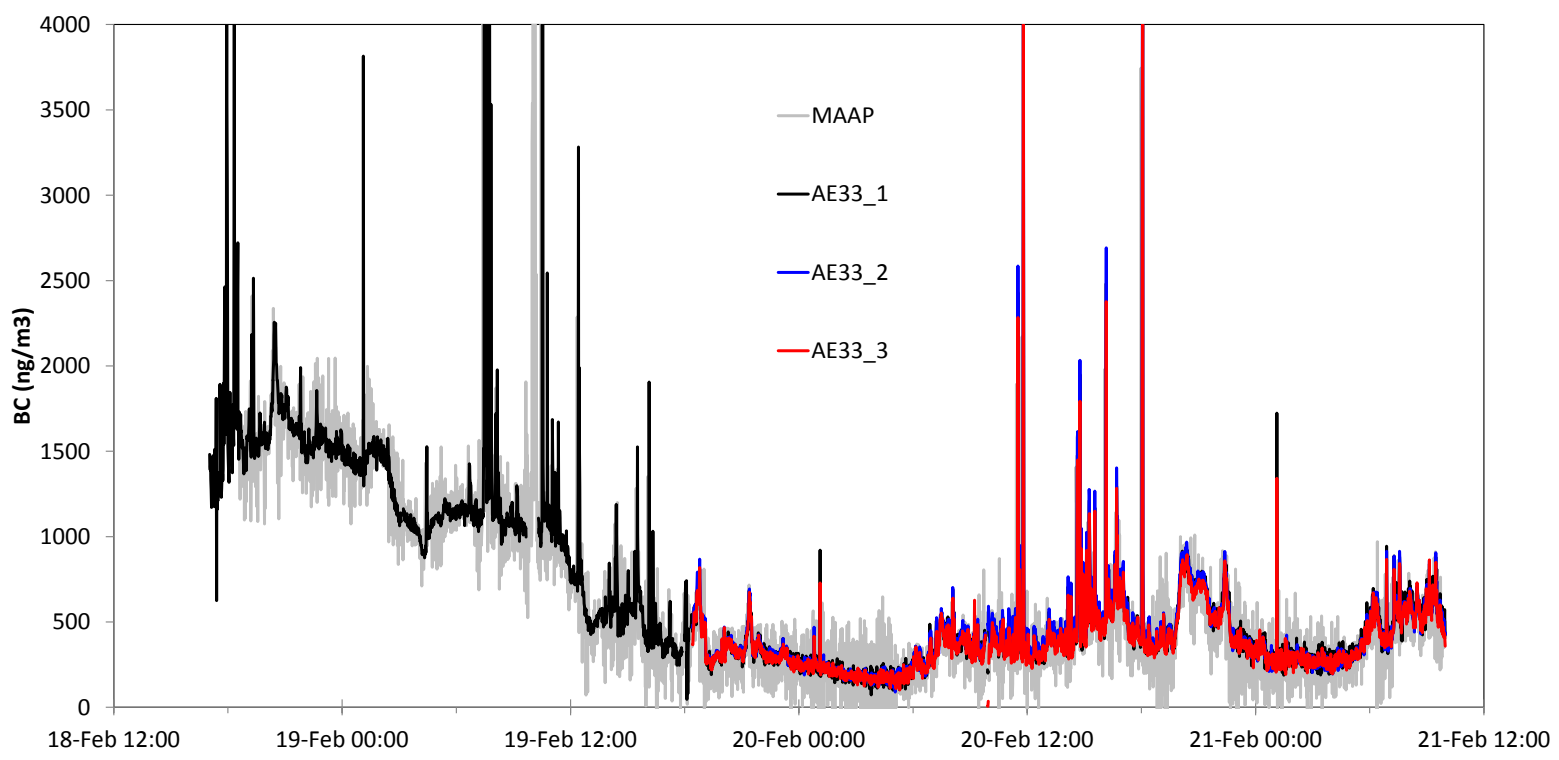

185 Figure S9. Time-series of the ACTRIS inter-comparison at TROPOS, showing AE33 and MAAP measurements of $\mathrm{BC}$. 


\section{References}

190

191

192

193

194

195

196

197

198

199

200

201

202

203

204

205

206

207

208

209

210

Babich P., Davey M., Allen G., and Koutrakis, P.: Method comparisons for particulate nitrate, elemental carbon, and PM2.5 mass in seven U.S. cities, J. Air Waste Manag. Assoc., 50, 1095105, 2000.

Bae, M.-S., Schauer, J. J., Turner, J. R., and Hopke, P. K., Seasonal variations of elemental carbon in urban aerosols as measured by two common thermal-optical carbon methods, Sci. Total Environ., 407, 5176-5183, doi:10.1016/j.scitotenv.2009.05.035, 2009.

Bond, T. C. and Bergstrom, R. W.: Light absorption by carbonaceous particles: An investigative review, Aerosol Sci. Technol., 40, 27-67, 2006.

Chiappini, L., Verlhac, S., Aujay, R., Maenhaut, W., Putaud, J. P., Sciare, J., Jaffrezo, J. L., Liousse, C., Galy-Lacaux, C., Alleman, L. Y., Panteliadis, P., Leoz, E., and Favez, O.: Clues for a standardised thermal-optical protocol for the assessment of organic and elemental carbon within ambient air particulate matter, Atmos. Meas. Tech., 7, 1649-1661, doi:10.5194/amt-7-1649-2014, 2014.

Fialho, P., Hansen, A. D. A., and Honrath, R. E.: Absorption coefficients by aerosols in remote areas: a new approach to decouple dust and black carbon absorption coefficients using sevenwavelength Aethalometer data, J. Aerosol Sci., 36, 267-282, 2005.

Gundel, L. A., Dod, R. L., and Novakov, T.: Determination of black carbon by thermal analysis, in Chapter from the Energy and Environment Division, Annual Report 1980, LBNL Paper LBL11986, 5-26-5-28, 1981.

Gundel, L. A., Dod, R. L., Rosen, H., and Novakov, T.: The relationship between optical attenuation and black carbon concentration for ambient and source particles, Sci. Total Environ., 36, 197202, doi:10.1016/0048-9697(84)90266-3, 1984.

Hansen, A. D. A.: The Aethalometer Manual. Magee Scientific, Berkeley, California, USA, 2005. 
Hansen, A. D. A., Rosen, H., and Novakov, T.: The aethalometer - an instrument for the real-time measurement of optical absorption by aerosol particles, Sci. Total Environ., 36, 191-196, 1984.

Malissa, H., Puxbaum, H., and Pell, E.: Zur simultanen relativkonduktometrischen Kohlenstoff-und Schwefelbestimmung in Stäuben. Z. Anal. Chem., 282, 109-113, 1976.

Moosmüller, H., Chakrabarty, R. K., Ehlers, K. M., and Arnott, W. P.: Absorption Ångström coefficient, brown carbon, and aerosols: basic concepts, bulk matter, and spherical particles, Atmos. Chem. Phys., 11, 1217-1225, doi:10.5194/acp-11-1217-2011, 2011.

Sandradewi, J., Prévôt, A. S. H., Weingartner, E., Schmidhauser, R., Gysel, M., and Baltensperger, U.: A study of wood burning and traffic aerosols in an Alpine valley using a multi-wavelength aethalometer, Atmos. Environ., 42, 101-112, 2008a.

Sandradewi, J., Prévôt, A. S. H., Szidat, S., Perron, N., Alfarra, M. R., Lanz, V. A., Weingartner, E., and Baltensperger, U.: Using aerosol light absorption measurements for the quantitative determination of wood burning and traffic emission contributions to particulate matter, Environ. Sci. Technol., 42, 3316-3323, doi:10.1021/es702253ms, 2008b.

Sciare, J., d' Argouges, O., Sarda-Estève, R., Gaimoz, C., Dolgorouky, C., Bonnaire, N., Favez, O., Bonsang, B., and Gros, V.: Large contribution of water-insoluble secondary organic aerosols in the region of Paris (France) during wintertime, J. Geophys. Res.-Atmos., 116, D22203, doi:10.1029/2011JD015756, 2011.

Weingartner, E., Saathoff, H., Schnaiter, M., Streit, N., Bitnar, B., and Baltensperger, U.: Absorption of light by soot particles: determination of the absorption coefficient by means of aethalometers, J. Aerosol Sci., 34, 1445-1463, doi:10.1016/S0021-8502(03)00359-8, 2003.

Yang, M., Howell, S. G., Zhuang, J., and Huebert, B. J.: Attribution of aerosol light absorption to black carbon, brown carbon, and dust in China - interpretations of atmospheric measurements during EAST-AIRE, Atmos. Chem. Phys., 9, 2035-2050, doi:10.5194/acp-9-2035-2009, 2009. 